\title{
How Does the First Language Have an Influence on Language Learning? A Case study in an English ESL Classroom
}

\author{
Yanilis Romero $^{1,2} \&$ Milton Pájaro Manjarres ${ }^{1,2}$ \\ ${ }^{1}$ Institución Educativa Antonia Santos, Montería, Córdoba, Colombia \\ ${ }^{2}$ Universidad de Córdoba, Montería, Córdoba, Colombia \\ Correspondence: Milton Pájaro Manjarres, Transversal 12 • 1-11 Barrio Galilea, Montería, Córdoba, Colombia. \\ Tel: 301-735-7916. E-mail: miltonpama@gmail.com
}

Received: March 7, 2017 Accepted: June 2, 2017 Online Published: June 6, 2017

doi: 10.5539/elt.v10n7p123 URL: http://doi.org/10.5539/elt.v10n7p123

\begin{abstract}
This article presents a case study which aims at analyzing the influence that the first language has on the learning of a foreign language. This research was conducted in an ESL classroom from a Language Center in England and was carried out with a Saudi Arabian student during a two-month period. In order to conduct this research, theoretical support about contrastive analysis (CA) and error analysis (EA) were taken into account. The findings of this case study suggested that CA and EA are effective ways to study and understand how the first language (L1) of a learner might have an influence on the learning process in a foreign language. In this particular case study, it was found that this Saudi Arabian learner had a better performance in receptive skills; there were some evidences of $U$ shape learning in this learner and also it was noticed that his handwriting and the use of punctuation marks although good, they needed some improvement.
\end{abstract}

Keywords: contrastive analysis, error analysis, case study, native language

\section{Introduction}

Perspectives on language learning and teaching bring a wide range of important aspects that need to be considered; some of them include culture and native language. These two features play an important role that might be overseen once language teachers start instructing. The first language or L1 (regardless of the country) becomes the first source for a learner to understand how a language works, specially to young learners who are in the concrete operation phase, as they tend to monitor how they acquire and learn foreign languages. Interestingly, the learning of foreign languages helps students to understand their native one, and they resort to their schemes of L1 to relate to the L2. In this sense, it is relevant to point the importance of students' first language when learning a foreign or second language.

Different researchers, such as Kramsch (1993), Byram and Grundy (2003), and Pulverness (2003) have recently studied the relationship that exists between culture and language learning. Holmes cited in Byram and Grundy (2003) for instance shows how culture is encoded in the conceptual metaphors speakers of a language are convinced of.

In other words, these encodings are not equal for all languages and for this reason, language instructors need to be aware of this situation in order to understand how the students learn, depending on the place they come from and the language they have as mother tongue.

This paper presents a case study carried out by two English Teachers with a Saudi Arabian student who belonged to a group of twelve learners learning English as a foreign language at a language institute in Southampton, England. Students' age range from 15 to 20.

The research group asked for a volunteer and explained the purpose of the study having as a result a Saudi Arabian student who volunteered to be part of the study.

This study had the purpose of conducting a Contrastive Analysis (CA) about the language learning process developed by the learner chosen in order to create a Language Learner Profile (LLP) based on the data collected. The purpose of all this is to help the student to do better at his language learning process. 
After identifying different needs, wants and lacks in this Saudi Arabian Learner, the researchers created a set of activities to help the learner cope with skills such as reading and listening. The importance of this piece of research is intended to raise awareness about a major inquiry underlying the teaching process dealing with planning, a phase in which instructors need to consider the heterogeneity of the target audience and the complexity of each students' needs.

\subsection{How Does the First Language Have an Influence over the Learning of a New Language?}

Language is essential if we want that habits, institutions and beliefs acquire the meaning of what we call culture. In fact, these aspects must have meaning to become culture. According to Kramsch (2013) language, not seen as a linguistic system, but seen in context is: "a coherent symbolic system for making meaning" (Kramsch, 2013: 62). In this sense, we cannot separate the study of language and language learning from culture and the context that surrounds the learner, especially when we refer to the learning of a foreign language.

Besides culture, the first language (L1) of a learner might have an influence over foreign language learning, either by acting as a source for the learner to understand how the language works when the first language and the foreign language are similar (transfer), or by being a factor of interference if the two languages are very different (negative transfer) (Celaya, M., n.d).

Although some authors such as Krashen (1982) and Dulay and Burt (1974) claim that the process of learning the L2 is similar to the one of learning the L1, some researchers like: Kellerman and Sharwood-Smith (1986) use the term "Crosslinguistic influence" to refer to aspects of language learning such as: transfer, avoidance and borrowing renewing the ideas of transference that appeared in the 50's and 60's giving some support to the ideas stated by Lado (1957) who stays that: "individuals tend to transfer the forms and meanings (...) of their native language and culture to the foreign language and culture" (Lado, 1957 cited in Celaya, n.d. :1)

The following case study presents an analysis on how the first language of a Saudi Arabian student learning English had an influence over his language learning process. The purpose of this analysis was to show English teachers how having an understanding of the influence that the L1 has over the learning of a second language can help to select better teaching materials, prepare more suitable lessons and give more effective instructions to our students

\subsection{Contrastive Analysis}

One of the key aspects that needs to be considered when talking about the influence that the L1 has over the learning of a foreign language is contrastive analysis (CA). According to Johansson (2008) contrastive analysis can be defined as: "the systematic comparison between two or more languages, with the aim of describing their similarities and differences". (p. 9) This kind of analysis usually has a pedagogical purpose and it is usually carried out to have better descriptions of the learners' performance and select better teaching materials for the learners. When someone is learning a foreign language, it is common to make mistakes in pronunciation or grammar as a result of the interference of the first language; it is here where CA is important because it allows the teacher and the learner to be aware of the difference that exist between two languages in order to learn the correct use of the foreign one.

\section{Methodology}

\subsection{The Case Study}

Different authors have defined case studies in different ways depending on their background as researchers. Merriam (1988) for instance states that: "Case study can be defined as an intensive, holistic description and analysis of a single entity, phenomenon, or social unit. Case studies are particularistic, descriptive, and heuristic and rely heavily on inductive reasoning in handling multiple data sources" (p. 16). One of the key aspects in this definition is the fact that the phenomenon is studied in context. Case studies are centered on description, inference and interpretation, rather than on a formal experiment where the variables are controlled and manipulated.

This case study particularly examines and analyses in detail the different strengths, weaknesses and challenges faced by a Saudi Arabian who studies English as a foreign language at an English language school in Southampton. This study helps teachers to raise awareness of individual differences among learners. Having a clear understanding about the characteristics of language learners allows teachers to reflect about the language needs of foreign students when preparing lessons and selecting teaching materials to effectively teach and guide them. 


\subsection{Participants}

The participant for this case study was a nineteen-year-old male from Saudi Arabia who was learning English at a Language Centre in England. This learner had been studying English for 2 months by the time this study was carried out. His plan was to finish the English course in six months because he needed the language for further education. He wanted to become a physiotherapist. His current English level by the time this case study took place was A 2.1 as it was revealed by the Quick Placement Test administered in the English institute at the beginning of the course. It is significant to highlight that the learner came just to study English, his economic background was good and his parents live in Saudi Arabia in the urban area of Makah city.

\subsection{Data Collection}

The data for this study was collected in a two-month period. During this time, an English language learner was selected to carry out different stages to determine what he needed to become a successful English language learner. This study was executed in two phases: the first one was called the discovery stage and the second one entitled action plan. The former was comprised by four diagnostic tasks: speaking, reading, writing and a listening one. All of them designed under careful regards of the participant's language level in that moment. In the second phase the researchers proposed an action plan and a series of one-to-one lesson.

In the discovery stage, the researchers considered suitable to apply just one task per skill since the purpose was to gain a general view of what the needs of the learner were. The main purpose in this stage was to make all these tasks enticing to the learner so he could be fully engaged avoiding to discourage him due to the workload proposed for the first phase of the investigation.

\subsubsection{Discovery Stage}

This phase started with a speaking task, then came the reading, listening and finally the writing one. The order was randomly proposed to the student who gladly accepted as the tasks were executed in the participant's free time.

In the oral task, the student was interviewed for about ten minutes by one of the researchers. The questions he was asked were intended to find if he was good at describing routines, talking about past actions, referring to other people in present or past and offering personal information.

Below it can be found the transcript of the interview, which was recorded while it took place. The format of the presentation is as follows:

Table 1. Transcription of the interview made to the student part 1

\begin{tabular}{|c|c|c|c|}
\hline TIME & Line & TURN & TRANSCRIPT \\
\hline & 1 & Teacher(T) & How about you? \\
\hline \multirow[t]{6}{*}{$00: 28$} & 2 & Student (St) & $\begin{array}{l}\text { My name is Juan Perez (Note 1), I am from Saudi Arabia. I'm } 19 \\
\text { years old }\end{array}$ \\
\hline & 3 & $\mathrm{~T}$ & Why are you here in Southampton \\
\hline & 4 & $\mathrm{ST}$ & $\begin{array}{l}\text { You mean here in England?, because I /studied/ because I want to } \\
\text { study a university in England }\end{array}$ \\
\hline & 5 & $\mathrm{~T}$ & In England, What are you going to study? \\
\hline & 6 & ST & I want to study, If you know the subject...physiotherapy. \\
\hline & 7 & $\mathrm{~T}$ & Why do you like that? It's difficult \\
\hline \multirow[t]{6}{*}{1.14} & 8 & ST & $\begin{array}{l}\text { Why, I think no difficult, it's not difficult.. Ahh I like it because when I } \\
\text { had this subject, I /can't/ work in my country. You know that }\end{array}$ \\
\hline & 9 & $\mathrm{~T}$ & What did you do yesterday? \\
\hline & 10 & $\mathrm{ST}$ & Yesterday, I was, no sorry I went to shopping, some shopping and.. \\
\hline & 11 & $\mathrm{~T}$ & Where? \\
\hline & 12 & ST & In the center of Southampton \\
\hline & 13 & $\mathrm{~T}$ & Did you buy food? \\
\hline
\end{tabular}




\begin{tabular}{|c|c|c|c|}
\hline & 14 & ST & Yeahh a little \\
\hline \multirow[t]{5}{*}{$1: 48$} & 15 & $\mathrm{~T}$ & Have you gone to another city here in London to another town? \\
\hline & 16 & ST & Yeah, I went to London, ... yeahh, I was in London \\
\hline & 17 & $\mathrm{~T}$ & Any other place around. Like have you been in another place here? \\
\hline & 18 & ST & Like Reading, Exeter, Winchester... And....Manchester... \\
\hline & 19 & $\mathrm{~T}$ & What are you doing during the afternoon? \\
\hline \multirow[t]{9}{*}{$2: 23$} & 20 & ST & Yeahh....in the afternoon, I have class \\
\hline & 21 & $\mathrm{~T}$ & Again? \\
\hline & 22 & ST & In the afternoon I have class \\
\hline & 23 & $\mathrm{~T}$ & Here? \\
\hline & 24 & ST & In this school \\
\hline & 25 & $\mathrm{~T}$ & Every day.. \\
\hline & 26 & & Yeahh everyday \\
\hline & 27 & $\mathrm{~T}$ & From what time to what time? \\
\hline & 28 & ST & $\begin{array}{l}\text { The class begin at } 2 \text { o'clock. Finish...... beginning } 2 \text { o'clock.....from } \\
2 \text { o'clock to ehh half past three. }\end{array}$ \\
\hline
\end{tabular}

\begin{tabular}{llllll}
\hline $2: 56$ & 29 & T & Wow...what do your parents do? Your mother.. What is her
\end{tabular} profession?

\begin{tabular}{llll}
\hline $3: 00$ & 30 & ST & He's not in England... she not sorry in England \\
\hline & 31 & T & Where is she? \\
\hline 32 & ST & In my country \\
\hline 33 & T & What does she do \\
\hline 34 & ST & Yes she.. Teach... she's teacher at school.. Like you I think \\
\hline $3: 23$ & 35 & T & In primary or secondary? \\
\hline
\end{tabular}

No...my father.. I think.. You know.. .. Electrical engineers.. But now he is /rettrid/ yeahh. Now is working.. He like free works like this ..Sometimes buy.. Pay a house and then sell, pay a house and sell.. Like this yeahh like this ...buy car sell car...(words in Arabic). Like this.

\begin{tabular}{llll}
\hline $3: 56$ & 39 & T & What does your father like? Like what does he like to do?, his hobbies \\
\hline 40 & ST & $\begin{array}{l}\text { I think my father ... old man.. I think.. Not.. He doesn't have any } \\
\text { hobby at all...like... }\end{array}$ \\
\hline 41 & T & And your mum? \\
\hline 42 & ST & Yeahh..The same... but my mum...she's home.. .ahh... I can doctor.. \\
\hline 43 & T & You are only child? Or do you have any.. \\
\hline 4443 & ST & $\begin{array}{l}\text { Yeah. Yeahh. I'm one.. I'm only child, but I have a new brother.. } \\
\text { Newborn.. Yeahh }\end{array}$ \\
\hline 45 & T & Yeahh little one? \\
\hline 46 & ST & This is one.. Yeahh \\
\hline 47 & T & Your mum.. Wow.. How old is he? \\
\hline 48 & ST & Yeahhh I think now he's aaa 18.. 8 months. I think so
\end{tabular}




\begin{tabular}{llll}
\hline & 49 & $\mathrm{~T}$ & 8 months \\
\hline 4.58 & 50 & $\mathrm{ST}$ & 8 months, but I never see, never see \\
\hline 51 & $\mathrm{~T}$ & Only pictures \\
\hline $5: 08$ & 53 & $\mathrm{ST}$ & Just the picture \\
\hline $5: 16$ & 54 & $\mathrm{ST}$ & $\begin{array}{l}\text { Nice... What will you do tomorrow.. Or during the class tomorrow } \\
\text { you're coming to class, right!, during the weekend }\end{array}$ \\
\hline & $\begin{array}{l}\text { Weekend...Sometimes, I go to center, to the city center, sometimes } \\
\text { stay at home, studying, yeahhh sometimes but every weekend, I should } \\
\text { call to my father or my family.. Every weekend.. }\end{array}$ \\
\hline
\end{tabular}

Note 1: Real name was changed for ethical purposes.

Table 2. Transcription of the interview made to the student part 2

\begin{tabular}{llll}
\hline TIME & Line & TURN & TRANSCRIPT \\
\hline 9:07 & 55 & ST & $\begin{array}{l}\text { The cover, they wear cover because this is me... name is /Nikap/ This } \\
\text { is.. .ehh they are wearing because this my religion Islam...yeah. My } \\
\text { religion.. tell us about this thing. Every woman you should.. they must } \\
\text { not ..should .yeah should wear this/ cover nikap/ this cover }\end{array}$ \\
\hline 9:36 & 56 & T & Why? \\
\hline & 57 & ST & This is my religion, no reason. No no religion \\
\hline & 58 & T & And the clothes? Also \\
\hline & 59 & ST & Yeahh? The clothes also \\
\hline $10: 04$ & 60 & T & They Shouldn't wear... \\
\hline $10: 18$ & 61 & ST & $\begin{array}{l}\text { Nikep .. and the.. You know... you know what's the name of this clothes } \\
\text { /abaia/... }\end{array}$ \\
\hline & 63 & T & ABIAH.. in Arabic.. \\
\hline
\end{tabular}

Concerning, the reading skill, the Arabic student was asked to read an article about football (See Appendix 3). The reason why the researchers chose this sport was that during the interview, the student manifested to like football. Another reason to present a theme of the student's interest was that it would be more pleasant for him to work on the task.

The reading task required focusing on two main aspects; one was the gist and the other was to find some specific information given in the text. The reading was about football, it presented a mix of different grammar tenses and the vocabulary included in it was appropriate for the level of the student. The text was long but comprehensible and it was perceived in the interview that the student could deal with extensive texts. This task had 5 questions; the first one was to assess if the student could read for the gist and the other four questions were about finding specific information within the text.

Regarding the listening task, it consisted of a two-minute video about natural physiotherapy treatments. The video was chosen because the student had manifested to be interested in this field when he was interviewed. Five questions were formulated after the student watched the video. One of them was asked to see if he could get the main idea of the video and the other four to check if he could get specific information from it. The material presented for this task was fair, bearing in mid his level and interests.

Before starting to listen, three words were chosen to be pre-taught as it was assumed that the learner would not know their meaning. The words were: apprehensive, wonder and reach.

Afterwards, the student watched and listened to the video twice and in between he spent some time writing the answers he recalled. The inquiries mentioned above are shown in Appendix 1. 
The last task proposed for the target student in the discovery stage, was to write a few lines describing his past life in his hometown and his life while living in London. Sixty minutes were given to the student to complete the assignment. Neither the dictionary, nor the smartphone were allowed during this task. He was inside a classroom with one of the researchers who monitored his performance during the writing activity.

The final product of this writing task can be seen in Appendix 2. Find in red and black all the corrections made after the task was completed. SPAG (Spelling, Punctuation, and Grammar) mistakes were found.

\section{Action Plan}

The second part of this research proposed an action plan which is presented in this article through a chart where the researchers clearly state the student's wants and needs. There is another chart which states the context of the language, the register, the skills and the suggested structure, functions and notions to be taught.

\subsection{Functions}

In terms of functions, the participant used various functions of the language in the four tasks presented. As follows:

- Giving opinions: like in the case when he said that physiotherapy was easy

- Predicting: when he needed to say how his life was going to be when he was working on the writing task.

- Describing: when he wrote about his life now and the way how his life was in the past.

- Expressing wishes: when he said, he wanted to study in England.

\subsection{General use}

The student can understand questions and vocabulary related to areas on immediate personal relevance. He can give basic personal and family information. He can catch questions in different grammar tenses, and attempt to answer them using basic structures. Also, the participant can briefly give reasons and explanations.

The student is not accurate but he tries to be fluent. He uses a lot of time fillers to monitor himself and give himself time to think.

Table 3. Action Plan: wants and needs

\begin{tabular}{|c|c|}
\hline WANTS & NEEDS \\
\hline $\begin{array}{l}\text { The student wants to learn English to become a } \\
\text { physiotherapist and he wants to gain more about } \\
\text { vocabulary related to the body and muscles. He also } \\
\text { wants to be able to write academic reports. }\end{array}$ & $\begin{array}{l}\text { He needs to build strong foundations of the language so } \\
\text { he can be accurate when conveying meaning. To become } \\
\text { a proficient user of the English language this learner } \\
\text { needs to work harder on the development of productive } \\
\text { skills. }\end{array}$ \\
\hline
\end{tabular}

Table 4. Action Plan: Context, register, skills, structure, function and notion

\section{CONTEXT (S) OF LANGUAGE ACTS}

The student is a young man who attends to the English classes and goes home after that. He sometimes hangs around with his friends but they are Arabs so he does not speak English with his friends. As a consequence, the use of his English is limited to the English classes as well as the interaction he has with his host family.

\section{REGISTER}

Currently, The student is not working; He just studies; for this reason, he needs to know when and how to use formal and informal language, taking into account the different situations he could be in.

\section{SKILLS}

The student needs to develop the four language skills for his future intentions to study a subject in England. To start with, speaking and writing which are the productive skills will be emphasized in the first lesson of the syllabus to be proposed.

\section{STRUCTURE, FUNCTION AND NOTION:}

The student needs a clear review of simple grammar tenses in present and past. He needs to talk about experiences and talk about his routine. 
Time available

5 different lessons of 60 minutes were carried out

After the action plan was designed, the research team executed the lessons and the findings after applying them are described below:

\section{$3.3 \mathrm{Aim}$}

The aim of this lesson was to help the student learn how to talk about his past experiences using regular verbs, and at the same time give him some controlled practice of the teaching points using his previous experience in Makah as a context.

\subsection{Lesson Plans}

To look at sample of the lesson plan applied see Appendix 4.

\section{Data Analysis}

\subsection{Findings of the Discovery Stage}

In the following lines a contrastive analysis of each of the tasks proposed in the four skills will be presented. This examination was made to the light of the Error Analysis (EA) theory. The main purpose of this examination was to perceive the points of difficulty that occurred through a systematic study of the learner's errors revealing the learner's difficulties to finally make a proposal about a possible strategy to overcome the difficulties. It is relevant to mention that the main variance from error and mistakes is that the former is caused due to the knowledge of the language and the other because the there is a slip of the tongue but the learner might correct it when there is awareness of it. For the purposes of this study the highlighted issues in the analysis are considered errors.

In the speaking analysis, the scrutiny was made in terms of phonology, structure and lexis. The layout to present the analysis contains six ranks: the type of error, the error as such, the correction, the analysis and source, and finally a suggested treatment for the error. The following table presents the findings in detail.

\subsubsection{Speaking Analysis}

Table 5. Speaking skill analysis regarding phonology

Type of error: Phonology

Error: (line 35 )/ braI,meri /brimary

Correction: / prai,meri /primary

Analysis: Both are allophonic sounds and tend to be used randomly.

Origin: Interference with the native language

Treatment: Reinforce the both sounds to make distinction of them with the IPA.

\section{Type of error: Phonology}

Error: (line 8) /kænt/

Correction: /kæn / Can positive form

Analysis: the learner is placing a plosive alveolar sound instead of a nasal alveolar one.

Origin: Arabic speaker often over pronounce post-vocalic sounds.

Treatment: IPA, modelling

Type of error: Phonology

Error: (line 38) /rretər/ reter

Correction: / ri'taird / retired

Analysis: the learner did not pronounce the $/ \mathrm{r} /$ instead he used the $/ \mathrm{rr} /$ sound

Origin: Arabic speaker often over pronounce post-vocalic sounds.

Treatment: IPA, modelling 
After analysing the interview, it could be found that this student had an inconvenient with the sound $/ \mathrm{p} / \mathrm{instead}$ of using this sound, he used the $/ \mathrm{b} /$ sound. The problem with this sound has to do with the fact that the Arabic people use the letter "P" but the sound is actually /b/. Other sounds such as: the one of the verb can probably was not learnt appropriately and he pronounced it as "can't". Some other sounds like the one of the word-retired need some modelling and drilling.

Table 6. Speaking skill analysis regarding structure

Type of error: Structure

Error: (line 8) no difficult

Correction: it's not difficult

Analysis: The learner used a general "no"

Origin: Arabic language does not have auxiliaries to make the negative form they just have a particle before the verb

Treatment: review the verb to be in negative form

Type of error: Structure

Error: (line 8) when I had this subject

Correction: when I study this subject

Analysis: The learner confuses the present simple with past simple

Origin: The U shape learning

Treatment: reinforce grammar structures through a possible given context

Type of error: Structure

Error: (line 10) I went to shopping

Correction: I went shopping

Analysis: The student knows that after the verb "go" is a "to"

Origin: The learner overgeneralised the rule and apply to after the verb go- went

Treatment: Explain when it is possible with to and without.

Type of error: Structure

Error: (line 28) the class begin at 2 o'clock... finish

Correction: the class begins at 2 o'clock... it finishes

Analysis: The "s" or the "es" are frequently omitted in the present simple.

Origin: The student is experiencing $\mathrm{U}$ shape learning

Treatment: Concept check - difference between present with singular and third person.

Type of error: Structure

Error: (line 40) I think my father old man

Correction: I think my father is an old man

Analysis: the student omitted the verb to be and the article

Origin: There is no verb to be in present in the Arabic language

Treatment: review the verb to be and concept check when to use it.

Type of error: Structure

Error: (line 50) I never see

Correction: I have never seen him

Analysis: The learner used the simple present to

Origin: Interlanguage, the learner used present simple because in the Arabic language the present perfect form 
refers to the past

Treatment: review the verb to be in negative form

The structural errors of this learner showed that he was struggling with differentiating grammar tenses. The learner's speech was not as elaborated as it should have been but he came across with his ideas. The learner needed some scaffolding and review of some structures such as: the present simple and the simple past.

From the previous analysis, it is possible to say that these errors may interfere with intelligibility. There were some high frequency errors like the omission of the third person singular "s".

It can be assumed that this student chose simple forms and constructions to avoid more complex ones as it can be seen in one of the boxes above where he was supposed to use present perfect but instead he used the simple present.

Table 7. Speaking skill analysis regarding lexis

Type of error: Lexical

Error: (line 37 )Free works

Correction: Free lancing

Analysis: Use of known vocabulary to express an idea with inauthentic language

Origin: He is resorting to words in order to keep his fluency

Treatment: Self-correction technique or reformulation of the words.

Type of error: Lexical

Error: (Line 38) He doesn't have any hobby

Correction: He doesn't have any hobbies

Analysis: He did not pluralized the word hobbies

Origin; The student omits the letter "s" to make plurals

Treatment: Model plural sounds and use IPA

Type of error: Lexical

Error: ( ) /Nikap/

Correction: Cover face

Analysis: he doesn't know the word in English

Origin: He needs to expand his vocabulary

Treatment: Reformulation technique to let him know the word in English.

Type of error: Lexical

Error: (line 60 ) Abayh

Correction:

Analysis: He used L1 to keep his fluency and not break down the communication

Origin: The learner's lexis is limited

Treatment: Reformulation technique to let him know the word in English.

The errors found in this part of the analysis showed that this learner tried to keep the conversation flowing making use of words in L1; which is not bad, but he could have used a different communication strategy like circumlocution to avoid using his native language.

Also, when he introduced a word in his L1, he noticed that it was ok, so he did it three times more, which evidenced that he was not imaginative to find ways in English to say what he wanted. 


\subsubsection{Reading Skill Analysis}

The reading part was analysed in view of how well the learner understood the text; his comprehension of the questions for the gist and details.

The student in this study engaged well with the reading task. He responded positively to the questions given and it was evident that he knew what he was asked about. He answered the five questions in twenty-five minutes after having read the text twice. Even though he could find the answers, it could be noticed that he provided few words to answer them. Although, the answers did not need a complete sentence to be answered, it would have been better if he would have used a whole utterance to reply the inquiries.

While reading, the learner could be seen skimming the text using his pencil to guide himself until he found the answers. He underlined the sentences where he thought the answers were.

He could get all the answers right, which was good because it was seen that he was able to understand and grasp the meaning of the text.

Some of the reasons why this learner succeeded with the task might be:

- Graded vocabulary

- Interest in the topic

- $\quad$ Background knowledge about the topic

\subsubsection{Listening Skill Analysis}

The listening part was analysed taking into account how well the learner understood the track and his comprehension of the questions for the gist and details.

It was noticed that the learner did not take any notes while he was listening. However, he was able to answer all the questions. This makes us think that the visual part of the video helped him to be accurate with the answers but still he had to listen carefully to come up with the appropriate words he needed to answer the questions.

On the other hand, it is possible to say that he did well not only because he saw the images in the video but also because he grasped meaning from what he listened to; otherwise he would not have got all the answer right.

The answer for the gist question was good; but he did not provide a written answer. After the learner watched the video and listened to it, he gave an account about the main topic of the video. He used his own words to explain his understanding of the video, which can be considered good because it is evident that he could understand what he listened to and finally he used this information to offer an answer.

Regarding the specific questions, the learner did a good job as all the answers were correct. He did not answer them giving complete sentences but they were correct. It could be seen that the student underlined some key words in the questions before listening, which was probably one of his strategies to effectively approach the listening task.

\subsubsection{Writing Skill Analysis}

The written production was analysed bearing in mind the grammatical accuracy, the lexical range, spelling and punctuation. The analysis in this skill was similar to the one applied for the speaking skill. The following table presents in detail the findings.

Table 8. Writing skill analysis regarding grammatical accuracy

Type of error: Grammatical accuracy

Error: live, have

Correction: lived, had

Analysis: the learner wrote in present rather than past

Origin: He may have problems with this grammar tense.

Type of error: Grammatical accuracy

Error: is died

Correction: died

Analysis: the learner wrote the fact in passive, but it should be in past. 
Origin: He has problem with using the past simple probably he has not internalized it yet.

Type of error: Grammatical accuracy

Error: I was sading

Correction: I was sad

Analysis: the learner does not recognize the adjective sad, instead he added the suffix ing.

Origin: He confused past tenses

Type of error: Grammatical accuracy

Error: I am live and I am study

Correction: I am living and I am studying

Analysis: the learner's intention was to use the present continuous to say he is actually living and studying but he did not add the suffix.

Origin: The Arabic language lacks of a present tense of the verb to be, so the student struggles with this form.

Type of error: Grammatical accuracy

Error: It will be change, my family will moving now

Correction: It will be changing, my family will be moving

Analysis: The learner was trying to use the future progressive, which is a complex structure. He probably forgot how to use the form properly

Origin: He is still learning the structure

Type of error: Grammatical accuracy

Error: I missed my family, I really missed them

Correction: I miss my family, I really miss them

Analysis: the learner confuses the present tense with the past tense. He is not sure of when to use them.

Origin: He probably was taught the past simple in isolation and no comparison was made with the present simple.

Type of error: Grammatical accuracy

Error: When I back

Correction: When I am/go back

Analysis: There is no verb in the sentence

Origin: There is no present tense of the verb to be which may cause this error

Table 9. Writing skill analysis regarding lexical range and accuracy

Type of error: Accuracy

Error: Friend

Correction: Friends

Analysis: the learner did not pluralize the word

Origin: he may have though that as the word is preceded by the quantifier a lot, it is already in plural.

Type of error: Lexical range

Error: I'll come back

Correction: I'll go back

Analysis: The student knows how the structure works; he needs to distinguish when it is "go back" or "come back"

Origin: He often uses 
Type of error: Lexical range

Error: before 1 year ago.

Correction: a year ago.

Analysis: the learner knows that these words relates to previous

Origin: he may have heard these two words to state a period time.

Table 10. Writing skill analysis regarding spelling and punctuation

Type of error: Spelling

Error: Fathe

Correction: Father

Analysis: The student did not write the " $\mathrm{r}$ " at the end of the word

Origin: It might have been a slip.

Type of error: Spelling

Error: I will be happy if something change

Correction: I will be happy if something changes

Analysis: He The student did not write the "s" at the end of the verb

Origin: It's difficult to master the use of "s", "es" in verbs in the present simple form.

The researchers asked the learner to write a paragraph about how his life was before coming to England and how he thinks it will be when he goes back to his country. The intention of this task was to explore how good he was at writing using different grammar structures and also assess his possible range of vocabulary regarding his personal life.

It was found that the learner might have showed behaviour of the $U$ shape learning, which means that he had already learned some of the structures that he needed to use in the writing task but when writing he had unlearned them as some other features of the L2 have been incorporated. This idea is based on the fact that according to the Common European Framework and the level where this learner was placed in the institute, he was supposed to know when and how to use appropriately different grammar tenses.

This learner used a passive structure, which is good regarding grammar, but it does not make any sense (see above tables). There are several mistakes related to grammar which give evidence that the learner did not consider the grammar tense to be used. On the contrary he misused other structures.

Some other errors were related to accuracy, spelling and punctuation which are considered minor errors as some of them could have been slips rather than errors as such.

It is important to highlight that the handwriting of this student was understandable and his use of the western alphabet was appropriate considering that he used characters to write in Arabic.

On the other hand, the learner demonstrated well use of some punctuation marks such as commas and full stops which was good. However, the text needed some other punctuation marks to be more comprehensible. As in Arabic, the use of punctuation marks is more flexible, this might have affected his writing production.

\subsection{Results of the Plan of Action}

The presentation part of the lessons was good. It was noticed when the participant was looking at the picture and he knew what to say. This learner might have found easy to work on the lesson because he was excited about the pictures and one of the teachers started to explain many other things about the city to him. Therefore, it was easy to elicit the target language, but as it was expected irregular verbs were mentioned, the teacher wrote them on the board and told him that the class was about past events but the emphasis was on regular verbs. The student was really engaged with the presentation of the language. He wanted to share his ideas about experiences and he knew the structure because he could identify regular verbs in past and explained to the teacher how to write the past form of these verbs by just adding the suffix "ed". Because of his enthusiasm, the presentation stage and the first controlled practice activity were outstanding. 
The reason why the participant felt motivated towards working on the topic was that he was interested on the topic, he had previous knowledge about it and the research team noticed, the student loved his country and his culture.

\subsubsection{What Might Be Changed in a Future Application of the Lessons?}

The research team considers that it would be a good idea to change the first controlled activity, which was too easy for this learner. The student showed to have studied the structure before; for this reason, he was able to cope well with this first controlled practice. A fill gap activity with no options could have been given so that the learner could have found a more challenging activity.

The teachers were not sure if the list of verbs chosen to practice the ending of regular verbs was good enough as it was perceived that the student did not really get the difference between the /d/ sound and the /t/ sound. The student did not recognize all the sounds in the IPA, which is not bad, but we believe that he needs more practice and modelling for some of the sounds while he is learning the language.

\subsubsection{The Student}

The student was punctual and he followed us wherever we asked him to go which was a sign that he really wanted to listen to what the researchers had to say or teach. The student showed a positive attitude all the time; he manifested interest in participating spontaneously in the different activities and he could provide explanations using his own words.

\subsubsection{Materials}

The research team had some pictures, some copies and a wall chart with some regular verbs.

\subsubsection{How Effective the Materials Were}

The materials used were good. For instance, the pictures used at the beginning of the lesson, helped the teachers to set the context and elicit the language needed. The utterances written were useful because the student could see the target language and used it. The reading activity was comprehensible and appropriate for the student's level.

\section{Conclusion}

In an educational setting, case studies are strong in terms of reality since through them, a phenomenon or social unit is studied in context. Some scholars claim that: Case studies clearly possess the potential for rich contextualization that can shed light on the complexities of language learning process. As it is known each human being is different and for this reason generalizing through a research can be a difficult process. It is here where case studies are important because they focus on the context as a key aspect to understand the phenomenon studied.

After having analysed the results of the different tasks applied to the subject of this study, it is possible to draw different conclusions. First, there is some evidence that this student had a better performance in tasks that involved receptive skills. This learner is able to cope better with listening and reading tasks, which means that there are more possibilities for the learner to achieve the purpose of learning if the skills are receptive. Second, some evidence of interlanguage and $U$ shape learning are presented because the learner is incorporating some features of the language that he had learned in his learning process during the development of different tasks. Also, it can be noticed that some of the structures already learned by this student need to be reinforced in context which could facilitate the learner to recycle what he has already learned. Besides that, the handwriting of the learner is passing through a development process and the use of punctuation marks need to be refined. Until now the performance of the learner in these two aspects is not bad; however, it can be improved. Finally, in regard to the pronunciation mistakes that are taking place as a result of interference from his native language, some modelling and drilling are required in order to improve pronunciation.

Regarding the action plan and the one to one lesson, the fact that the materials and the topic chosen for the lesson were interesting for the learner, made it easy for him to work on all the activities proposed; therefore, it was easy to elicit the target language as it was expected. However, for a further application of this lesson it would be a good idea to make the controlled activity more challenging as the learner found it very easy.

The use of contrastive analysis and error analysis facilitated the process of understanding what aspects of the L1 where having some interference or effect over the learning process of this Arabian learner. Having clearly identified these aspects, made it possible to plan suitable lessons, tasks and activities for this particular learner. 


\section{References}

Byram, M., \& Grundy, P. (2003). Context and culture in language learning and teaching. U.K. Multilingual Matters.

Celaya, M. (n.d.). (2016). The Role of the L1 in the Acquisition and Use of the L2: New Perspectives. Retrieved July 20th, 2016, from: http://www.raco.cat/index.php/bells/article/viewFile/98198/148953

Council of Europe. (2001). Common European Framework of Reference for Languages. Cambridge: Cambridge University Press.

Dulay, H., \& Burt, M. K. (1974). Natural Sequences in Child SLA. Language Learning, 24(1), 37-68. https://doi.org/10.1111/j.1467-1770.1974.tb00234.x

Johansson, S. (2008). Contrastive Analysis and Learner Langange: A Corpus-based Approach. Oslo: Oslo University.

Kellerman, E., \& Sharwood, M. (1986). Crosslinguistic Influence in Second Language Acquisition. Pearson College Division.

Kramsch, C. (1993). Context and Culture in Language Teaching. Retrieved, July 18th, 2016, from http://eric.ed.gov/?id=ED371633

Kramsch, C. (2013). Cuture in Foreign Language Teaching. Retrieved July, 18th, 2016, from http://faculty.weber.edu/cbergeson/516/kramsch.2012.pdf

Krashen, S. (1982). Principles and Practice in Second Language Acquisition. Oxford: Pergamon Press.

Mackey, A., \& Gass, S. M. (2005). Second Language Research: Methodology and design. Mahawah, NJ: Lawrence Erlbaum Associates.

Merriam, S. B. (1988). Case study research in education: A qualitative approach. San Francisco: Jossey-Bass.

Pulverness, A. (2003). Distinctions \& Dichotomies: Culture-free, Culture-bound. Retrieved July, 18th, 2016, from http://elt.britcoun.org.pl/forum/distanddich.htm.

\section{Appendices}

Appendix 1. Inquiries about the video watched

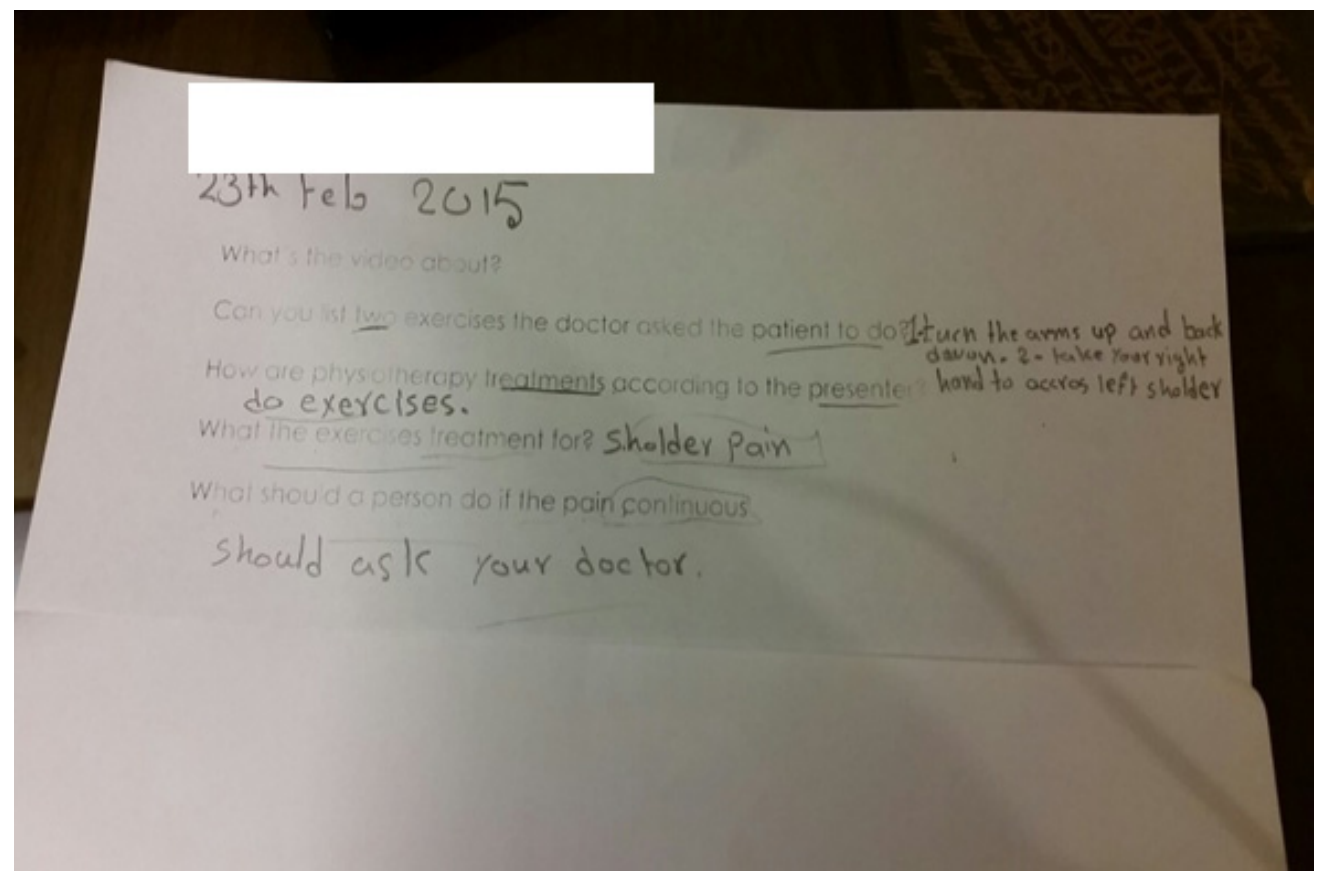


Appendix 2. Writing task about the learner's past life in his hometown and the his life nowadays

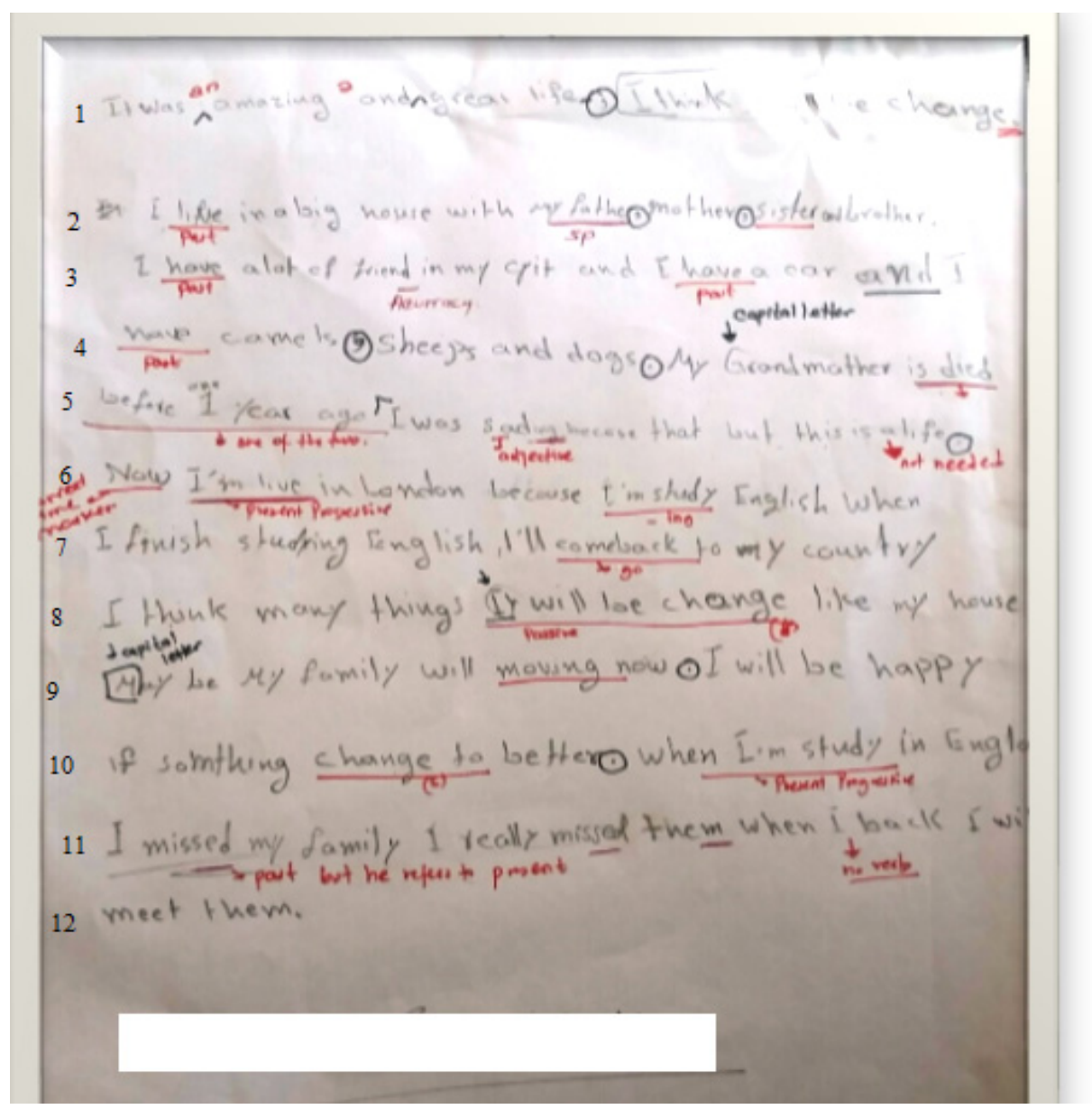

Appendix 3

Name
READING COMPREHENSION
The American type of football was developed in the 19th century from soccer and rugby football. Played by
professionals, college students, high school teens, or young children, football in America is one of the most
popular sports. It attracts millions of fans each fall and people are very supportive of their favorite teams. The
origin or beginning of football may have been a game played by the ancient Greeks called harpaston.
In this game, there was no limit to the number of players. The ball was kicked, thrown, or run by the players and
the object was to move a ball across a goal by kicking.
The football playing field of today is rectangular in shape and measures 100 yards long and 53.5 yards wide.
White lines are painted on the playing field to mark off the distances to the end zone. The game is divided into
four quarters, each fifteen minutes long. The first two quarters are known as the first half. There is a rest period
between the two halves which usually lasts about fifteen minutes.
Each team has eleven players. Each team has offensive players (play when the team has possession of the ball)
and defensive players (play when the other team has possession of the ball).
Players are required to wear protective equipment to help keep the body safe during the game. Helmets are worn
to protect the head and face area. Pads are worn to protect the shoulders, arms, and legs. Protective equipment
must be worn because of the body contact players have during the game. The football is made of leather and is
brown in color. It is shaped much like an oval and has white rings near each end of the football.
These rings help the players see the ball when it is thrown or someone is running with it. The eight stitches on
the top of the football help players to grip or hold the ball when throwing or passing. The most famous football


game of the year is the Super Bowl that is played in January or February. It is televised around the world and is watched by millions of people each year.

\section{The Questions were:}

\section{Task 1 Read the text once and answer the question below}

1. What is the text about? Explain in your own words.

Task 2 Read again and answer the following questions

2. What is the most famous football game each year?

3. What shape is the football?

4. Why are there white rings on each end of the football?

5. Who plays American football?

The student's answers were:

1. The text is about football. In this game there was no limit to the numbers of players. In this game you should be strong like an ox.

2. The super bowl

3. Oval

4. To help players see the ball

5. Professional layers, college players and high school players. 
Appendix 4

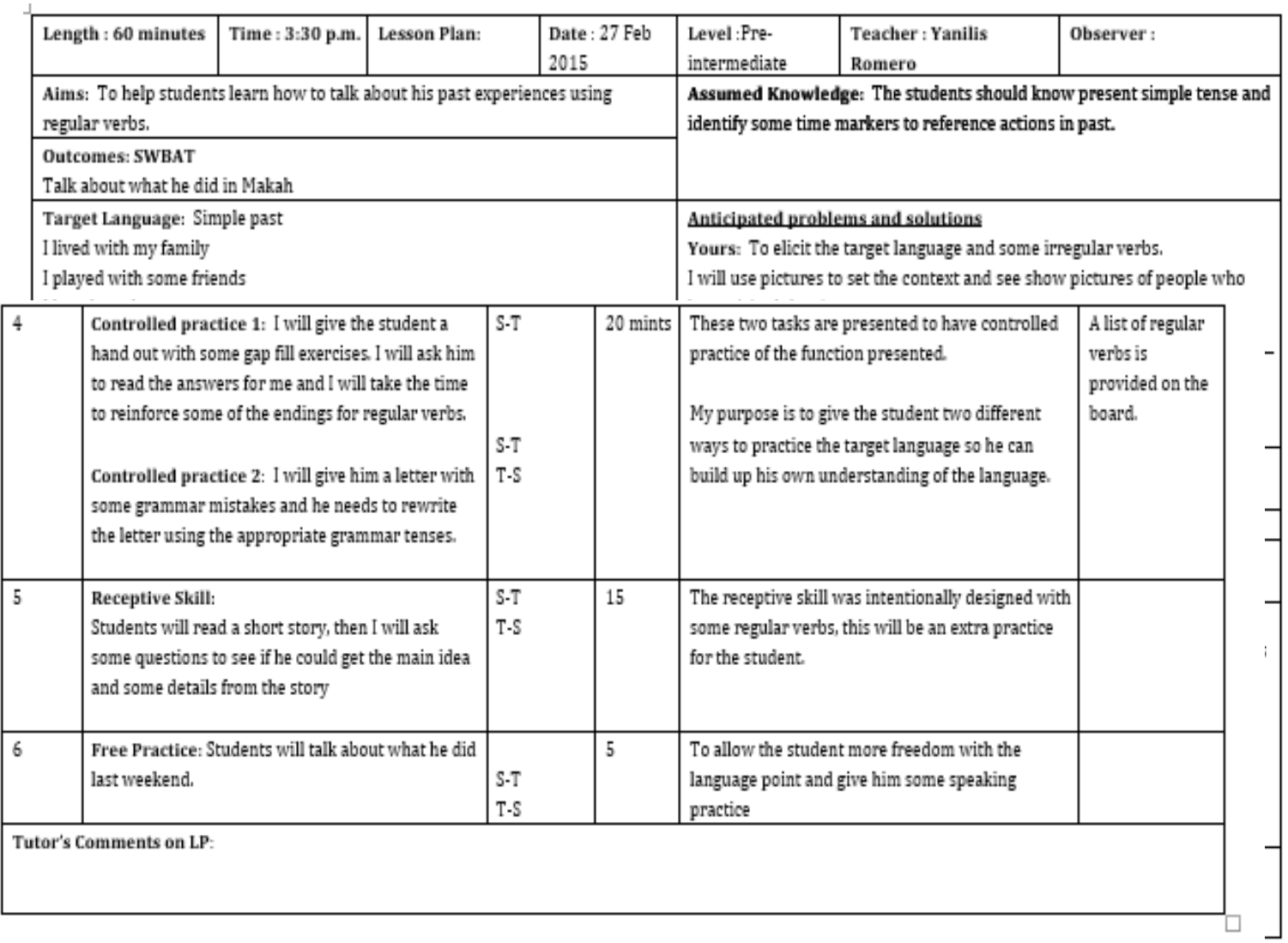

This lesson may include materials which I might decide to include in the MatA $(\mathrm{m} / \mathrm{N}$ )

\section{Copyrights}

Copyright for this article is retained by the author(s), with first publication rights granted to the journal.

This is an open-access article distributed under the terms and conditions of the Creative Commons Attribution license (http://creativecommons.org/licenses/by/4.0/). 